\title{
The Chinese Approach to the Liberal Concept of Human Rights
}

\author{
Shuresh Moradi \\ Tsinghua University School of Law, Beijing, China \\ Email: shuresh.mor@gmail.com
}

How to cite this paper: Moradi, S. (2019) The Chinese Approach to the Liberal Concept of Human Rights. Open Journal of Social Sciences, 7, 249-258.

https://doi.org/10.4236/jss.2019.79019

Received: July 25, 2019

Accepted: September 23, 2019

Published: September 26, 2019

Copyright $\odot 2019$ by author(s) and Scientific Research Publishing Inc. This work is licensed under the Creative Commons Attribution International License (CC BY 4.0).

http://creativecommons.org/licenses/by/4.0/

\begin{abstract}
The contemporary discourse regarding Human Rights in China is highly polarized and controversial. Whilst the Chinese constitution declares that "the State respects and preserves human rights [1]", the Western governments do not agree on its theoretical interpretation nor implementation. Simultaneously, the project of liberal democracy and multiculturalism in the West is being questioned. The working theory of this research focuses on the main legal framework of the PRC and its practical and theoretical approach to the liberal concept of human rights.
\end{abstract}

\section{Keywords}

Human Rights, China, Liberalism

\section{Introduction}

Within the nation state, the ultimate organ responsible for guaranteeing human rights is fundamentally the state itself. However, more often than not, it is that same organ that breaches the rights it was responsible for protecting. Similarly, the state is often the organ that chooses to disregard human rights when it comes into direct conflict with state specific interests.

Although human rights are growing increasingly stronger, the limit of state sovereignty is still highly controversial. The nation state is still the determining unit in the global political arena. It could however be questioned whether that will always remain the case. Transnational and liberal projects such as the European Union (EU) have led to a certain degree of limitation of national sovereignty. The European nations have also, to a greater extent than the United States (US), ratified international conventions and treaties that constitute the basis for human rights. The project of the EU is developing towards a universal 
order of strong rights as well as harmonization with national legislation. In the US, on the other hand, there is a great division between those who believe that the nation should be active in international politics, and those who adhere to a more isolationist approach. Antonio Scalia [2] has expressed that all form of implementation of international law that is not already consistent with national law, goes against American interest and constitute an intrusion in the national sovereignty. On the other hand, the US is a nation that often refers to human rights as a motive for economic sanctions and military interventions.

Despite conflicting definitions of human rights and the increase of human rights breaches, it can today be perceived that human rights is in fact developing to become a part of a bigger context to which all states must relate to in one way or another. Individual states can no longer simply disregard international human rights. Even the People's Republic of China must take a valid stance in relation to international human rights.

\section{Jurisprudential Background}

The theoretical development of the Chinese concept of "human rights with Chinese characteristics" has been extensively promoted by well renowned scholars such as Li Yunlong [3] and Liu Hainan [4]. The theory of "human rights with Chinese characteristics" must be seen a response to the liberal idea of human rights which stems from the continental philosophical theory of natural rights. As opposed to the mainstream western scholarship where the cultural aspect of China and its approach to human rights is discussed [5], the Chinese academics rarely approach the issue with a cultural focus. The main focus of the Chinese scholars is on the Chinese socialist ideology its understanding of human rights [6]. The center for this theoretical formulation can be mainly found in the China Society of Human Rights Studies which constituted one of the largest mainland Chinese NGO's focused on human rights and which also publishes its magazine "Human Rights". The theory presented in Human Rights often follow the main anti-traditionalist approach of the CPC arguing against the feudal heritage of traditional culture [7]. This marks yet another distinction between Western and Chinese scholarship in regards to the cultural relevance and interpretation of the theory of human rights in China [8]. The resistance to the traditionalist approach can be found in the May Fourth Movement, which represents the historical lesson that traditionalism was not successful in averting the humiliation of the West in the $19^{\text {th }}$ century. This resulted in an anti-traditionalist approach which continued with the Cultural Revolution. The legacy of these two historical events came to lay the foundation of contemporary thought in regards to human rights and its source of legitimacy. This is well noted in the Chinese reaction to the approach of Lee Kuan Yew, the former Prime Minister of Singapore, and his focus on "the cultural" to rebuke the individualism that characterized the West. His promotion of "Asian Values", referring to the adaptation of human rights to national and cultural conditions [9], was a stark reaction against the universalism of the western liberal concept of human rights. The argument of Asian val- 
ues was however not an approach promoted nor officially accepted by the PRC. More interestingly, the Chinese human rights discourse aimed less at relating to Asia and more to the "Third World" [10]. This stance was of an ideological nature, rather than cultural. By rejecting the universalist-relativist approach of Western scholarship the Chinese discourse takes a more holistic approach by referring to the "universal" and the "particular" as inextricably related [11]. It is the ideals and common needs that give rise to the universal whilst the implementation of the rights in a given context is that which provides the particular. These two concepts must be respected equally in order to not betray either the universality or particularity of human rights [12]. The western approach to this issue is two-fold, either it attempts to reconcile itself with the idea of a plural world and varying corresponding moralities, which is incompatible with the idea of a superior and universal moral value, or it promotes western moral values on other cultures, continuing a dangerous historical path of imperialist heritage. This division between the two approaches does not merely appear on a practical level but also on a jurisprudential one, hindering a deep understanding of one another.

\section{Legislation}

The Chinese constitution, written in 1982 under Deng Xiaoping, is divided into four main parts of which 23 articles directly concern human rights. The People's Republic of China (PRC) official stance is that it respects and guarantees the basic human under the constitution. As support for this claim the article 34 regarding universal suffrage, article 35 guaranteeing freedom of speech, of the press, of assembly, of association are often mentioned. Moreover, women's and children's rights are guaranteed and protected by the constitution, as are the rights of the elderly as well as the economic rights.

What could, however, be regarded as remarkable are the articles 51, 53 and 54 where article 51 states that the above mentioned rights may not infringe upon the interest of the state. In other words, if the interest of the state conflicts with that of an individual, the interest of the state has precedent. Article 53 states that citizens must abide by the law and act with respect for social ethics. Moreover, article 54 continues to state that none of the above mentioned rights may conflict with the interest of the state. The international criticism of china is unified when accusing the paragraphs as mere formalities. In sum, legislation that guarantees and protects the basic human rights but that are simultaneously subordinate the interest of the state and the country as a whole becomes rather toothless from a liberal perspective where the individual, as opposed to the collective, is in focus.

The PRC has signed as well as ratified the International Covenant on Economic, Social and Cultural Rights (ICESCR) [13], International Convention on the Elimination of All Forms of Racial Discrimination [14], Convention Against Torture and Other Cruel, Inhuman or Degrading Treatment or Punishment [15] Convention on the Rights of the Child [16], Convention on the Elimination of 
All Forms of Discrimination Against Women [17]. Furthermore, the PRC has signed the International Covenant on Civil and Political Rights (ICCPR) but has not ratified the documents and thus is not legally binding [18]. The majority of accusations against China are based on CPR violations, and as china has not ratified the ICCPR, there is no international legal instance with jurisdiction over China. China opted out of human rights treaty clause that allowed a referral of violations to the International Court of Justice or an arbitration tribunal. Moreover, there is no international executive force strong enough to enforce punishment against China. As a permanent member of the UN Security Council and can veto resolutions it perceives as hostile.

International institutions and organizations such as the United Nations $\mathrm{Hu}$ man Rights Council, the European Court of Human Rights and the International Criminal Court, have been assigned to evaluate and determine how these conventions, treaties and other documents and norms are enforced and implemented [19]. In addition, the international norms of the type customary law as well as jus cogens can are also taken into consideration as they can be binding for states even in the absence of a formal treaty. However, the absence of universal consensus regarding the definition results in great inefficiency in terms of enforcement and implementation increases the complexity of the claim of universality of the concept of human rights that has its basis in nonbinding declarations such as the Vienna Declaration and Programme of Action [20].

\section{Critique of the Liberal Approach to Human Rights}

In the 21st century the liberal Western societies have continued to hold the promise of the 18th century demand for liberal equality while maintaining a social structure that to a great extent also disregards the de facto economic inequality in society. The liberal ideology is presented in terms of rationality, equal opportunity and win-win situations. Alternative approaches to socio-economic organization as well as institution are often quickly excluded as non-viable or legitimate alternatives. This development indicates two fundamental problems; one regarding the purely liberal definition of human rights, and the other regards the concept of legitimacy.

It cannot be denied that human rights have developed into a norm for legitimizing governance in Europe. The fact that the liberal definition of human rights are regarded as a legitimizing norm does not mean that it automatically will or should be regarded as a human right whose concept we in the future ought to strive towards. Instead, certain emphasis must be put on the shallow nature of the liberal concept itself and strive for a more in-depth understanding of human rights. The human rights must be given an expansive definition and a deeper content to fully put in practice its theoretical aim otherwise it risks becoming a pure formality. The dangers of a purely liberal definition with no internal analysis of the concept is that it risks leaving its dynamic nature for a static one, thus risking to land in the deep waters of pure nominalist rejection of the universal. 
Yet another issue that must be addressed when analyzing the concept of human rights is the implementation of sanctions. Specifically problematic is the use of intervention by military means. This issue is of crucial importance as it also deals with most of the liberal countries colonial past and the contemporary global power structures in both political and socio-economic terms. If human rights are understood as a moral right, directly tied to a corresponding duty for outsiders to offer protection, the question that must be raised is what measures are legitimate to enforce the protection of human rights? Can unilateral interventions be accepted? Do interventions in the name of human right risk constituting an expression of an arbitrary exercise of power without actual legitimacy? Unilateral interventions are prohibited in article 2 of the UN charter. Yet breaches of article 2 in the last decade has lead to none or few legal consequences. The UN as an international organization has proven unable to see to these situations satisfactorily. International organizations exist and reflect an already prevailing power structure within the global society. The main goal of the UN at the time of its establishment was the maintenance of stability in the world order emphasized even above justice. The idea and implementation of justice as a universal concept is more complex and presents far more challenges than the promotion of order. The problem of the superiority of order above justice is its reproductive function of a hierarchical status quo.

The debate on human rights and its liberal definition is progressively progressing from pure formalia to more substance. The concept of human rights must be understood in a social and economic context with a greater depth in order to maintain its dynamic nature and its potential for change and progress. Otherwise, the dangers of a static and institutionalized nature could prove to present challenges in the future [21].

\section{The Chinese Approach to the Universality of Human Rights}

The events on the Tiananmen square in 1989 sparked a widely spread debate both within the country as well as internationally regarding human rights in the PRC. In the international arena, China is frequently criticized by the Western liberal powers as well as NGO's and other international Institutions in regards to Human Rights. A consistent theme of criticism is the alleged reluctance or inability of the PRC to implement the laws regarding human rights. The critique presented mainly emphasizes the political system of a one-party state with autocratic rule where allegedly breaches of human rights occur continuously. The criticism focuses mainly on the civil and political rights. The alleged lack or great restrictions on the freedom of speech, thought and associations as well as religion, where religious activities are only allowed in state-controlled organizations, the rights and discrimination of ethnic minorities, the one child policy, the lack of Rule of Law and judicial independence, the various cases of police brutality and capital punishment and so on and so forth.

The PRC responds by emphasizing its progress of its economic, social and 
cultural rights, as they lay the foundation for the civil and political rights. The fact that certain reforms have been introduced and that parts of the population live under considerably more favorable conditions today than 40 years ago is often emphasized. A truly unprecedented economic development that permeates all aspects of societal life. The positive development of the Chinese society when compared to the post-era of 1949 is apparent and even though the development is slow it appears somewhat steady and in the right direction.

The PRC takes a more pragmatic approach by essentially regarding human rights as related to the level of development of the cultural and economic aspects of society. The PRC's philosophical stance, resonating with the idea of economic development, is the important role the collective holds. When the individual interest collides with the collective, it is the greater good that has precedent. LuiHuaqui, as the representative of China to the Vienna conference in 1993 stated that an "individual must not place his own rights and interests above those of the state and society" [22]. However, one should tread carefully when regarding this approach as philosophically utilitarian as it should be better understood in the light of materialistic dialectic philosophy.

More explanation is needed regarding the economic development and human rights. The fundamental idea is that economic and social development are necessary to ensure the civil and political rights. For a developing country, like that of China, the basic necessities such as shelter, food, clothing must be met firstly, mainly through the promotion of economic development.

The pragmatism is apparent as the improved standard of life is given more priority in than civil and political rights [22]. Yet another example of the pragmatic approach is that despite the fact that the PRC emphasizes economic social and cultural rights, the idea of the universality of human rights has not been opposed to theoretically [23]. The theoretical tendency of a relativit approach is noticed even in the aspect that if human rights values are universal, the implementation differs according to the economic base of society. Moreover, human rights and their corresponding definition are a historical product influenced and shaped by the different levels and directions of development. History, as a materialist dialectic concept, is a dynamic process influenced and shaped by socio-political, historio-cultural and economic conditions. The different development stages inevitably also lead to different interpretation as well as implementations of human rights. Therefore, the claim of universality, falls short in the light of historical materialism.

In regards to sovereignty, the PRC adopting the theoretical framework presented above, regards the concept of human rights as subordinate national sovereignty [22]. Liu Huaqui stated that the PRC's official position is that no country can use human rights concerns as a pretext to interfere with other countries internal affairs [22]. The emphasis on sovereignty and relativism stands in stark contrast to the liberal and more often than not western Universalist approach human rights as superior to sovereignty.

Despite the claim of absolute universalism. The claim of universality is not, in 
practical terms, absolute. A certain level of adaptation to social, cultural and economic conditions is inevitable. Of essential importance is determining the clear line between adaptation to particular conditions of a country and pure relativism. If the PRC claims that a certain level of adaptation to Chinese socio-economic and cultural conditions, the universalist theory will deem the Chinese approach as relativism and this not reconcilable with the universal concept of human rights. This claim, even if in theory valid, in practice falls short since even within liberal states with the rule of law levels of adaptation to national particularities are de facto very much the reality where they determine whether certain constitutional rights have precedent over others. Moreover, one should tread carefully when regarding the absolute nature of the universality of human rights. Values, norms, laws do not exist in a vacuum and to promote one approach claiming it to be not only absolute but in its universal essence also objective and thus value-free is to entirely disregard the subjective forces, drawing from social economic and cultural history that give rise to theories, structures that are inherently subjective and thus promoting the superiority of one approach o another. It would not be an exaggeration to claim that the current international order and the liberal concept of human rights does to a great extent promote a value system that is inherently western.

\section{Conclusions}

As the Western scholarship focuses on the merits of traditional Chinese thought the Chinese holistic approach of the universal and particular in regards to human rights are denounced as a form of relativism. The Chinese approach is generally not of a cultural nature which can be seen as a direct result of the historical legacy of the May fourth Movement and the Cultural Revolution. The Chinese approach to human rights distinguishes itself from the Western philosophical tradition of naturalism by emphasizing the collective in relation to the individual, and thus accordingly see legal rights as a means rather than an end in itself. Moreover, it emphasizes sovereignty and particularity over universalism, insisting on national particularities influence on universal human rights rather than vice versa.

Comparing China to other countries in its economic development range, the protection and promotion of ESCR is strong and continues to be encouraged and protected. However, regarding the CMHR in international law has a rather shaky legal basis. The absence of a legal instance to exercise jurisdiction over China is lacking. Moreover, despite the Western opposition, the voting trends in the UN's HRC suggest that the CMHR are becoming increasingly accepted by the international community. A far extending approach of particularity in relation to the CMHR may constitute a threat to the universal nature of human rights, simultaneously taking into account the possibility that continental philosophy and its western idea of naturalism may also constitute a particularity itself.

The historical legacy of colonialism has made the Chinese discourse more 
sensible to considerations of national pride and stability preservation than in the West. The universalist-relativist paradigm cannot invalidate the CMHR, because it is an ideological doctrine that cannot be accused of cultural relativism. Moreover, the gap between the Western and Chinese scholarship does not appear to decrease. Instead, the increasing economic growth and power of China gives rise to a Chinese alternative immune from the pressures of Western powers.

It is of pivotal importance to take into account how the economic development has affected a country's relation to not only itself but also to the surrounding world. During the European Enlightenment in the $18^{\text {th }}$ Century a confidence and trust in the European and Western model grew and came to be regarded as the correct one resulting in a belief in its superiority of the Western nation to others. This can most clearly be seen in the Colonial era. During the 1980s and 1990's when the economic development in china started taking form, the Chinese state begun to claim their own greatness and their own cultural particularity, similarly to what the Europeans had done for centuries. In Europe, the First and Second World War came to act as a catalyst for human rights and through these rights the national sovereignty was limited. A similar development did however not take place in China. The economic stability and confidence must be put in relation to a strong national culture and a strong sense of national identity. A national identity is partly constituted by a common history and tradition where a strong national identity strengthens nationalism. A belief in one's own system and culture could result in a state refuting liberal human rights as a purely western idea. In a historical light, the PRC lives in the memory of previous humiliation by the Europeans a century ago which could also prove to function as a unifying force by strengthen nationalism, resulting in suspicion regarding certain western values such as the contemporary liberal concept of human rights. In other words, if this path is continued, a strong sense of human rights, which is not by necessity in contradiction to Chinese values could be refuted due to its symbolic value of the west. A Chinese value system of human rights must gradually become a part of the Chinese culture and not only regarded as a western concept in order to be successfully implemented.

Due to the different level of economic development it would be inappropriate to compare the current state of the PRC with that of a developed western nation. A proper comparison that can shed an honest light on the situation in the PRC must take into account the economic development. Even since the gradual process of opening up to the world and the free market beginning in the end of the 70 's, changes are taking place in relation to human rights as well as people's understanding and demand of human rights. However, to mechanically implement liberal political and civil rights without further consideration of the history, culture and economic development of the PRC would be highly risky as the results could be devastating. To maintain a level of stability but yet aim to implement the human rights fully it must go hand in hand with the economic and cultural development of the nation. This process must be gradual as to not compromise the stability within the nation Moreover, the full transition from a feud- 
al culture to a modern capitalist culture takes considerably longer time than implementing economic reforms. Despite the increased wealth and improved living standards of vast parts of the Chinese population, the culture needs to undergo a gradual and slow progress in the same direction. Only when the superstructures correspond to the base can the society be more or less stable but during times of transition the process must not be hastened. In sum, from an international perspective as well as national, human rights are fundamental when it comes to achieving social and political stability within a nation, and it is in the best interest of both the people as well as the government.

Lastly, in regards to the liberal example of human rights, it is crucial for the PRC to analyze the success and failure of liberal human rights. Never before have Europeans criticized the liberal project as they are at the moment. One of the main issues of liberal human rights is the disparity between the formality and the de facto reality of people. In sum, the criticism focuses on the formality of law where we are equal before the law however the de facto inequality in society is not taken into as much consideration. The increased demand for a deepening of human rights is growing stronger in the European nations. The worry then is how liberal human rights can be given a deeper meaning without giving rise to social unrest? The greatest accomplishment of the PRC in regards to the future of the human rights debate would be to refute any dogmatic approach and instead with a dialectic method find a third path, that goes deeper than liberal and formal concept of human rights to decrease the disparity between the theory and practice. As a final remark, the question whether China will integrate the current world order or give rise to its own and whether human rights will be preserved in a Western sense, or influenced and transformed by the CMHR as the world is becoming increasingly multipolar, needs further research to be able to be said with certainty.

\section{Research Reason and Objective}

The main objective of this paper is to discuss and clarify China's approach to the Western concept of human rights, by putting it into the historio-cultural and economic context of contemporary China.

\section{Conflicts of Interest}

The author declares no conflicts of interest regarding the publication of this paper.

\section{References}

[1] Constitution of the People's Republic of China (1982) Art. 33 (After a 2004 Amendment)

[2] Scalia, A. Associate Justice of the Supreme Court of the United States.

[3] Li Y.L. (2014) The Development Path for Human Rights with Chinese Characteristics. Human Rights, 12.

[4] Liu, H.N. (2011) On Building Theoretical System of Human Rights with Chinese 
Characteristics. Human Rights, 10.

[5] Baehrs, P. (1996) Human Rights: Chinese and Dutch Perspectives. Springer, Berlin.

[6] Gu, C. (2011) For a Socialist Theoretical System for Human Rights with Chinese Characteristics. China Human Rights, 10.

http://www.chinahumanrights.org/CSHRS/Magazine/Text/t20110324_724148.htm Xian, K.L. (2012) The Logic of the System of Socialist Human Rights Theory with Chinese Characteristics.

[7] Paltiel, J. (1998) Human Rights and Chinese Tradition in Political Discourse. Confucianism and Human Rights, 273.

[8] Weatherley, R. (1999) The Discourse of Human Rights in China, Historical and Ideological Perspectives. Palgrave Macmillan, London.

de Bary, T. (1998) Asian Values and Human Rights. A Confucian Communitarian Perspective. Harvard University Press, Cambridge, MA.

Rosemont Jr., H. (1998) Human Rights: A Bill of Worries. Confucianism and Human Rights, 60.

[9] Zakaria, F. and Lee, K.Y. (1994) Culture Is Destiny: A Conversation with Lee Kuan Yew. Foreign Affairs, 73, 109-126. https://doi.org/10.2307/20045923

[10] Svensson, M. (2002) Debating Human Rights in China: A Political and Conceptual History. Rowman \& Littlefield Publishers, Lanham, MD.

[11] Liu, H. (1996) Human Rights Perspective in Diversified Cultures. Human Rights; Chinese and Dutch Perspectives, 18.

[12] Sun, P.H. (2014) Human Rights Protection System in China. 132.

[13] United Nations (1966) International Covenant on Economic, Social and Cultural Rights.

[14] United Nations (1966) International Convention on the Elimination of all Forms of Racial Discrimination.

[15] OHCHR (1984) Convention against Torture and Other Cruel, Inhuman or Degrading Treatment or Punishment.

[16] UNICEF (1989) Convention on the Rights of the Child.

[17] United Nations (1979) Convention on the Elimination of All Forms of Discrimination against Women.

[18] United Nations (1966) International Covenant on Civil and Political Rights.

[19] United Nations (1948) The Universal Declaration of Human Rights.

[20] OHCHR (1993) Vienna Declaration and Programme of Action. http://www.ohchr.org/en/professionalinterest/pages/vienna.aspx

[21] Koskenniemi, M. (2011) The Politics of International Law. Hart Publishing, Oxford.

[22] Liu, H.Q. (1993) Vienna Conference Statement. Reprinted in the Chinese Human Rights Reader: Documents and Commentary 1900-2000, 393 (2001).

[23] As Opposed to Non-Secular States that Oppose to the Concept of Human Rights on an Ideological and Theoretical Basis. 